\title{
Changes in the properties of semi-synthetic motor oil Castrol 10W-40 during its use in the diesel engine of commercial vehicles
}

Roman Prokop, Oleh Hrynyshyn, Taras Chervinskyy

Lviv Polytechnic National University, 12, Bandery St., 79013 Lviv, Ukraine ${ }^{\circledR}$ ogrynyshyn@ukr.net

\begin{abstract}
The changes in operational and physico-chemical properties of original and used semisynthetic motor oil Castrol 10W-40 before and after its use in a diesel engine have been investigated. Derivatographic studies were carried out to examine a thermal stability; IR spectroscopy was used to confirm the presence of oil aging products. The composition of the inorganic part of the studied semisynthetic oils was established by X-ray fluorescence analysis.
\end{abstract}

Keywords: semi-synthetic motor oil, used oil, thermal decomposition, oil aging, X-ray fluorescence analysis, IR spectroscopy.

The main consumers of lubricating oils are machine-building and automobile industries; automobile, railway, aviation and sea transport; fuel and energy complex, etc. The traditional basis of these products is mineral oils, the amount of which varies within 96-98\%. However, despite a low cost of mineral lubricating oils, they have a number of negative properties, in particular, low biodegradability, relatively high toxicity, limited shelf life and so on.

Nowadays, at the time of rapid development, renewal and improvement of many sectors of the economy, the task of creating and improving highly biodegradable lubricating materials is becoming increasingly important. One of the ways to produce environmentally friendly lubricants is to create new and improve existing formulations of semi-synthetic and synthetic motor oils with a long service life due to the addition of synthetic and polymeric materials. This solution to the long-term problem allows to release a significant part of the mineral base of lubricating oils, increase their service life in internal combustion engines (ICE) and significantly increase the service life of ICE [1].

During operation in ICE the motor oils undergo significant changes: water flooding, contamination with mechanical impurities and residues of unburned fuel, changes in chemical composition, etc. The composition of used motor oils includes pollutants, decomposition products of additives, heavy metals and acids, products of oil thermal decomposition, products of various chemical transformations of oil hydrocarbon part, etc. The toxicity of used oils (UO) is increased with the increase of molecular weight, acid value (AI), as well as the content of arenes, asphalt-resinous substances and sulfur compounds. More than 140 carcinogenic compounds have been identified in UO, in particular, benzo( $\alpha)$ pyrene, fenatren, etc. The amount of these hazardous compounds increases with increasing service life of engine oil in ICE and negatively affects the environment and public health. The combination of the processes, which leads to the deterioration of the operationl properties of motor oil, is called the oil aging. However, despite numerous studies the essence of this phenomenon remains controversial and not fully understood [2].

To date, semi-synthetic motor oils are one of the most popular groups of oils used in diesel engines of regional and international vehicles (commercial class). Due to the lack of attention paid to the study of aging processes of such motor oils, they were selected as the object of research. The study on changes in their properties after using in ICE will establish the probable causes and mechanism of oil aging. At the same time, the obtained results will be used to select the optimal regeneration technology for used semi-synthetic motor oils (USSO).

So, the purpose of this work is to study the change in performance of original and used semi-synthetic motor oil Castrol 10W-40, their thermal stability, changes in the inorganic part, search and confirmation of the presence of primary aging products in the used oil. 
The densities of the above oils were determined by the pycnometric method, the viscosity - by the viscometric method; the refractive index was determined using a refractometer, and the flash point - using an open cup device.

To determine the elemental composition of oils the X-ray fluorescence spectral analysis was performed on a mobile precision analyzer EXPERT 3L, designed to determine the mass fraction of chemical elements in homogeneous monolithic and powdery objects. Oil samples for the analysis were burned at $723 \mathrm{~K}$ for $4 \mathrm{~h}$, cooled in a desiccator and ground to a powder.

It was found (Table 1) that used semi-synthetic motor oil is characterized by lower viscosity and viscosity index, compared with those values of original oil. This change is explained by the fact that during the diesel engine operation in different modes under various mechanical and thermal loads a certain amount of diesel fuel, which has not burned in the engine, passes into the motor oil and dilutes it. This is confirmed by a decrease in the oil flash point due to the presence of diesel residues. Moreover, the group hydrocarbon composition of USSO is changed, which is confirmed by changes in the refractive index. At the same time, the used oil Castrol 10W-40 is characterized by a higher value of water content and mechanical impurities than original oil, which indicates the wear of the cylinder-piston group parts during ICE operation under different thermal loads. The coking ability of the oil increases, which is obviously also the result of changes in group composition. However, the most important defective indicator of oil aging is the value of the acid number, which increases as well. As a result, the oil acquires aggressive properties to metal parts of the engine, which will lead to chemical destruction of their surface.

Table 1

Physico-chemical characteristics of original and used Castrol 10W-40

\begin{tabular}{|l|c|c|}
\hline \multicolumn{1}{|c|}{ Index } & Original oil & Used oil \\
\hline Viscosity, $\mathrm{mm}^{2} / \mathrm{s}:$ & & \\
$-\quad$ at $323 \mathrm{~K}, v_{50}$ & 62.61 & 84.86 \\
$-\quad$ at $373 \mathrm{~K}, v_{100}$ & 12.46 & 11.97 \\
$\quad \quad v_{50} / \nu_{100}$ & 5.00 & 7.09 \\
\hline$\quad$ Viscosity index & 120 & 60 \\
\hline Density, kg/m ${ }^{3}$ & 863.0 & 879.7 \\
\hline Water content, \% & 0.06 & 0.15 \\
\hline Mechanical impurities & 0.63 & 1.24 \\
content, \% & 0.73 & 1.55 \\
\hline Coking ability, \% & 1.4692 & 1.4806 \\
\hline Refractive index, $\mathrm{n}_{\mathrm{D}}{ }^{20}$ & $<253$ & 253.5 \\
\hline Freezing point, K & 490 & 474 \\
\hline Flash point (open cup), K & 1.54 & 2.25 \\
\hline Acid number, mg KOH/g & & \\
\hline
\end{tabular}

Today, car manufacturers, namely Detroit Diesel, Caterpillar, Cummins and others, strictly regulate the metal content in motor oils. Thus, the above car manufacturers recommend to replace the engine oil with a new one when the content of such metals as iron, chromium, lead, copper, tin, aluminum, sodium, potassium and non-metals (silicon, boron) in the working oil exceeds the allowable one $(15-150 \mathrm{ppm})$. Excessive increase in the content of metals is one of the reasons for motor oil replacement.

The experimental results are presented in Table 2. 
Elemental composition of the inorganic part of the semi-synthetic motor oil Castrol 10W-

40

\begin{tabular}{|c|c|c|}
\hline \multirow{2}{*}{ Element } & \multicolumn{2}{|c|}{ Content, \% } \\
\cline { 2 - 3 } & Original oil & Used oil \\
\hline $\mathrm{Si}$ & $0.950 \pm 0.029$ & $1.141 \pm 0.032$ \\
\hline $\mathrm{P}$ & $4.428 \pm 0.022$ & $4.834 \pm 0.023$ \\
\hline $\mathrm{S}$ & $3.959 \pm 0.018$ & $4.193 \pm 0.017$ \\
\hline $\mathrm{Ca}$ & $41.800 \pm 0.091$ & $36.694 \pm 0.098$ \\
\hline $\mathrm{Cr}$ & - & $0.058 \pm 0.011$ \\
\hline $\mathrm{Fe}$ & $0.106 \pm 0.006$ & $0.544 \pm 0.010$ \\
\hline $\mathrm{Cu}$ & $0.011 \pm 0.004$ & $0.223 \pm 0.005$ \\
\hline $\mathrm{Zn}$ & $14.626 \pm 0.053$ & $18.582 \pm 0.059$ \\
\hline $\mathrm{Mo}$ & $0.719 \pm 0.005$ & $0.240 \pm 0.003$ \\
\hline $\mathrm{Pb}$ & - & $0.035 \pm 0.002$ \\
\hline
\end{tabular}

Analyzing the obtained results (Table 3 ) we can state the following: phosphorus, sulfur, and zinc indicate the presence of antioxidant and anti-wear additives in the oil (for example, DF11, LANI-317, Anti Wear, ZDDP, etc.); calcium, chromium, iron and copper reveal the presence of detergent-dispersing additives (for example, SC-3); molybdenum and lead characterize the presence of friction additives (for example, $\mathrm{MoS}_{2}$, lead naphthenate), as well as corrosion inhibitors and remetallizers.

The change in the content of above-mentioned metals indicates the presence of wear elements of the ICE cylinder-piston group, as well as the ingress of unwanted mechanical contaminants into the oil. The above-identified metals (iron, molybdenum, lead) contained in USSO, are mandatory components of metal alloys of parts of any engine. During its operation, microscopic metal particles are erased from the work surfaces and get into the engine oil. Thus, iron is the main structural material of the most important parts: cylinder block, cylinder head, valves, crankshafts and camshafts, connecting rods, piston pins, oil pump. The increased content of iron in the used oil usually indicates wear of one or more engine components. Titanium, which is characterized by its strength, is the main element of the alloy used for turbines, springs and valves manufacture. Molybdenum, as a wear-resistant metal, is most commonly found in piston rings and rolling bearings. Lead is often used for babbit based coatings, as well as for doping alloys used for connecting rods and bearing pad of crankshaft. The lead content in the used oil indicates the wear of the crankshaft bearings, etc. The decrease in calcium content in USSO indicates the depletion of detergent-dispersing additives or corrosion inhibitors. Phosphorus and sulfur in small quantities allow the surfaces of metal parts to be chemically inert. The increase in their content indicates the wear of the metal surfaces.

Another reason for the increase in inorganic components content is the addition of a new portion of oil between its changes. Typically, this is done for engines with significant mileage (approaching the repair period) in order to compensate the oil losses from burning and leakage. In this case, only the organic part of the oil burns out, and inorganic components accumulate in the oil, which circulates in the lubrication system of ICE.

[1] Hrynyshyn O., Korchak B., Chervinskyy T., Kochubei V.: Chem. Chem. Technol., 2017, 11, 387. https://doi.org/10.23939/chcht11.03.387

[2] Korchak B., Hrynyshyn O., Chervinskyy T., Polyuzhin I.: Chem. Chem. Technol., 2018, 12, 365.

https://doi.org/10.23939/chcht12.03.365 